\title{
Professional Knowledges for Early Childhood Education and Care
}

\author{
Verity Campbell-Barr
}

\begin{abstract}
Verity Campbell-Barr is an associate professor in early childhood studies at the University of Plymouth. She has over 15 years of experience researching early childhood service provision and related policy developments. Her research interests centre on the quality of early childhood services, with a particular focus on the role of the early childhood workforce in facilitating "quality." In 2015 she spent 18 months in Hungary undertaking a Marie Curie European research fellowship (funded by the European Commission) considering the knowledge, skills, and attitudes for working in early childhood education and care services. Most recently she has embarked on a research project considering interpretations of child-centred practice in different European countries in support of quality early childhood education and care. Email: verity.campbell-barr@plymouth.ac.uk
\end{abstract}

\section{This article proposes reconceptualizing} professional knowledge in early childhood education and care (ECEC) as knowledges, incorporating phronesis (practical wisdom), techne (skill), and episteme (pure knowledge). Conceptualizing professional knowledge in the plural broadens perspectives on the professional knowledge base and opens up a discussion of how different forms of knowledge are acquired. Drawing on Bernstein, the author identifies ECEC as requiring horizontal and vertical constructs of knowledge that have different structures and legitimization processes. While phronesis is presented as being a part of ECEC professional knowledges, the discussion explores the difficulties in defining phronesis, because of the variable ways it is articulated.

Keywords: knowledges; professionalism; phronesis; ethics
Specialized knowledge is core to the identification of a profession (Young \& Muller, 2014), but within early childhood education and care (ECEC), concepts of professional knowledge are much debated. In this article I present an argument for a plurality of specialized professional knowledge for ECEC, but identify challenges in articulating all forms of knowledge. Drawing on Basil Bernstein's sociological work on knowledge $(1999,2000)$ and those who have iterated it (e.g., Hordern, 2016; Young \& Muller, 2014; Winch, 2014) in relation to ECEC professionalism enables a consideration of knowledges, their different structures, and how they are developed and legitimized. Having outlined Bernstein's sociology of knowledge to provide a theoretical framework for the article, I present Aristotle's three forms of knowledge: episteme (pure knowledge), techne (skills) and phronesis (practical wisdom) as a structure for discussing knowledges. I focus on phronesis, considering what it is and what it might constitute within the ECEC knowledge base. I emphasize that phronesis is a considered and learned knowledge and an important component of the ECEC knowledge base that should be considered at all stages of professional development.

My discussion is set within the context of debates on quality and professionalism internationally. An international discussion creates challenges of how to refer to those working in ECEC given the variable training requirements that exist internationally. I refer to professionals and ECEC as general terms to represent those who work in care and education services for children from birth to just prior to starting school. Later I discuss the challenges of professional as a term, particularly in light of circumstances where there are no, or minimal, qualification requirements. While qualifications do not equate to professionalism and professionalism is not a given predictor of quality ECEC, both are concerned with the knowledge base to be acquired that represents the focus of the paper. The exploration of knowledges for ECEC seeks to broaden perspectives on the ECEC knowledge base and to recognize the complexities of professional learning in ECEC. 


\section{Bernstein's theory of knowledge}

Bernstein (1999) developed a sociology of knowledge to consider different knowledge structures and their validity. He identified horizontal and vertical discourses, where the everyday and common sense are expressed as horizontal, with all actors having access to it, creating a common nucleus, but where differences between the repertoires result in the meaning from one segment not being translatable to another. The language of horizontal discourse is shared within a group, where there is a taken-for-granted knowledge base, but one that does not extend beyond the group; the knowledge is transmitted locally. For example, the local practice developed within the workplace, such as daily care routines, illustrates horizontal knowledge.

Vertical discourse can take two forms, one that has a hierarchical structure, the other horizontal. Given the potential confusion between horizontal discourse and horizontal structures, I adopt Jim Hordern's (2017) use of vertical discourse with hierarchical and segmented (horizontal) structures. Vertical discourse with a hierarchical structure is coherent, explicit, and structured and has a specialized language which can speak to other knowledge and history (Young \& Muller, 2007). These features facilitate the distribution of vertical, hierarchically structured knowledge, enabling it to be challenged and defended. The physical sciences offer an example of vertical, hierarchically structured knowledge, with an established methodological and empirical base (Bernstein, 1999). Vertical, segmented knowledge is compartmentalized, with specialized language and modes of interrogation. Bernstein (2000) distinguishes between segments that have strong grammars, with explicit and formalized rules, and those with weak grammars, where there is a weaker relationship between the internal conception and the external language of description (Hordern, 2016) and the legitimacy of the knowledge is uncertain. Bernstein offers sociology as an example of vertical knowledge with a horizontal structure and weak grammar (Bernstein, 1999), while math and economics have strong grammars.

The disciplines that influence the ECEC knowledge base (e.g., psychology, sociology, philosophy, education) could generally be considered vertical discourses, with varying structures and grammars (Hordern, 2017; RheddingJones, 2005) that are recontextualized to meet the needs of practice. For example, theories on child development have been prominent within ECEC, representing knowledge that is identified as having value and significance (Hordern, 2016). While an assumption could be made that it is knowledge that is vertical, hierarchical, and with a strong grammar that is valuable, for an applied profession such as ECEC, propositional knowledge ("knowthat") is not sufficient because members of the ECEC workforce will need to "know-how" to apply and evaluate the knowledge (Winch, 2014). Bernstein attempted to illustrate that professionals draw on a variety of forms of knowledge, encompassing both horizontal and vertical, with the relationship between the different forms of knowledge often subtle, not differentiated and binary. ECEC therefore requires a combination of knowledges, both vertical (with varying structures and grammars) and horizontal, that combine in subtle ways so that individuals "know-how" to meet the demands of professional practice.

Bernstein (2000) created a distinction between singulars, regions, and fields of practice to illustrate the coming together of knowledges and their application. A singular can most easily be understood as an academic discipline, while regions represent the bringing together of different disciplines. Importantly, Bernstein understood regions as facing in two directions, one towards singulars, but the other towards fields of practice, the specialized, practical, and tacit knowledge that informs professional practice. The structuring of knowledge influences the forming of professional identities (Bernstein, 2000), whereby in an applied discipline the value of a singular is generated through its recontextualization, where the knowledge is delocated and relocated to face the field of practice (Hordern, 2017). Singulars into a region is a process whereby professionals make sense of academic disciplines for the context of their professional practice. For example, the value of a discipline such as psychology will be determined by how it meets the complexities of professional practice. However, rather than a linear process of 
singulars into regions and regions into fields of practice, Bernstein also considers how regions draw on knowledge generated in practice. The model provides a framework with which to consider how knowledges come together to inform ECEC professional practice.

In considering the combination of knowledges for ECEC professional practice, it is the less structured (less explicit) forms of knowledge that I am interested in. Poststructural and ecological perspectives of ECEC professionals (Dahlberg, Moss, \& Pence, 2013; Dalli, 2014), have begun to broaden understandings of professional knowledge through an ethical lens, with an emphasis on "doing the right thing" (morally) as opposed to "applying the right techniques." The ethical focus identifies with the importance of professional knowledge as being underpinned by multiple forms of knowledge, but I am interested in contemplating the knowledges that are harder to articulate and scrutinize. Sociological perspectives of professional knowledge enable an appreciation of the complexities of the ECEC professional knowledge base and coming to know-how to work with young children, which is significant for considering how ECEC preservice and in-service training is developed.

\section{Conceptual framework}

The challenges in articulating knowledges for ECEC leads me to draw upon Aristotle's three forms of knowledgeepisteme (pure knowledge), techne (skills), and phronesis (practical wisdom) - to organize my discussion on knowledges. ECEC has its origins in episteme and techne. Episteme, or pure knowledge, has a high cultural value, with recognized expertise, while techne represents more vocational knowledge or technical skills (Andrew, 2015). Together, episteme and techne represent the coming together of theory and practice in ECEC professionalism.

Phronesis is more difficult to articulate and is a debated term (Breier \& Ralphs, 2009; Finnigan, 2015; Russell, 2014). Broadly, phronesis represents the practical "spur of the moment" actions that are embedded in understanding the other, incorporating both the individual and the universal (Gade, 2014). Phronesis is a situated awareness of ethical values in action that is not separate from other forms of knowing (Winch, 2010) and, as I will argue, is central in bringing together knowledges for ECEC. The taken-for-grantedness of phronesis (Florian \& Graham, 2014) assumes the presence of values and beliefs in the guiding of daily practice, but phronesis is a "deliberative excellence" to find the correct and beneficial course of action (Russell, 2014). Within Bernstein's model, episteme has to be applied as a form of techne within applied professions such as ECEC, illustrating the notion of informing the action of professional practice.

Phronesis is rarely referred to explicitly in the literature on ECEC. Rather, variable terms are used to describe this additional form of knowledge (e.g., ethos, ethic, attitude, disposition), with an even more varied language to describe the various attributes of this form of knowledge (e.g., love, patience, sensitivity, empathy, awareness, respect for others, people who want to make a difference, passion, warmth, being emotionally accessible, reflexivity). My intention is not to present phronesis as a definition or an all-encompassing term that masks the variable language of what it represents, but to enable a critical review of the ECEC knowledge base.

\section{Quality and professionalism}

Examining professional knowledges for ECEC recognizes the limitations of standardized, rational, and technocratic approaches to determining quality ECEC and professionalism, with limited interpretations of what is valid knowledge. Modernist constructs of quality have sought to identify objective assessments of the provision of ECEC services, whereby quality is about predictability and reliability, ensuring the right techniques can be applied to achieve the right outcomes (Dahlberg et al., 2013). Jayne Osgood (2014) challenges the "know and fix" mentality of modernist constructs of quality that are underpinned by established ideas of the becoming 
child, characterized by developmentalism and increasingly joined by selective representations of neuroscience to inform how to perform quality ECEC. Economic debates on the function of quality ECEC also prove persuasive. Quality ECEC is identified as contributing to the "normal child," who will, it is supposed, require less economic intervention from the state as they progress into adulthood (Campbell-Barr, 2012); this lens views atypical children as only problematic when they require additional expenditures by the state. The discourse of quality has become synonymous with professionalism, whereby there is a focus on the right person to achieve the right outcomes, reflecting a normative and governing (modernist) interpretation (Cameron \& Moss, 2007; Urban, 2008).

Professionalization agendas are contentious; they include debates on what constitutes a profession and whether ECECis a recognized profession (Brock, 2006; Moyles, 2001; Osgood, 2006), revealing a tension between perspectives focused on standardization and models that enable professional autonomy based on professional judgment (Young \& Muller, 2014). Michel Vandenbroeck and his colleagues Jan Peeters and Maria Bouverne-De Bie (2013) explore how understandings of professionalism and working in ECEC became technocratic, underpinned by a concept of the entrepreneurial self; their work reflects Osgood's $(2004,2006)$ critiques of masculine and rational approaches to professionalism in ECEC. The ECEC professional reflects a concern with creating the right worker to produce the right child outcomes, but in neoliberal economies, entrepreneurialism and economic competitiveness are also required to ensure sustainable businesses that adhere to policy requirements (Osgood, 2004). Concepts of professional knowledge become narrowly focused on economic competitiveness, evident at the individual level of having the knowledge to succeed, but also for service providers to be successful entrepreneurs with viable businesses. The rational, technocratic, and entrepreneurial construction of professionalism is problematic for understanding the ECEC knowledge base and the role of the workforce in determining concepts of professionalism. Knowledge is that which can be identified and assessed, frequently determined through a top-down process that privileges policy objectives over the views of professionals (Cottle \& Alexander, 2012; Moloney, 2010).

The presumed objective reliability of modernist approaches to quality ECEC and professionalism are challenged when looking at contradictions across Europe. Europe has common goals and terms of reference from the European Commission (e.g., Council of the European Commission, 2011; European Commission, 2014) for the provision of quality ECEC, but huge variations in the ECEC services provided, particularly when analyzing workforce requirements (Urban, 2008). Oberhuemer, Schreyer, and Neuman (2010), in a cross-European study, considered the range of ECEC professionals that exist. The varying job titles indicate not only a lack of agreement on the structure of the workforce for quality ECEC, but also different conceptions of ECEC and an associated professionalism. The varied concepts of professionalism will depend on the training undertaken and the ECEC services that people work in, with some services encompassing different professional roles, such as teachers and assistants. The cultural variances inevitably have different adherences to modernist principles of professionalism. Concepts of professionalism combine with images of children and childhood and have implications for the ECEC knowledge base, including knowledge that extends beyond standardization and rationality. Professional knowledge for ECEC is therefore not about universal understandings of ECEC or seeking to mask the differences that exist between those working in ECEC, but opening up debates on what the knowledge base is and the multiple ways of knowing for working in ECEC.

\section{Multiple forms of knowledge}

The struggle around the nature of knowledge within professional competence models for ECEC (Hordern, 2016) sees some forms of knowledge favoured over others. Yarrow Andrew (2015) discusses the privileging of episteme (pure knowledge) in Western education systems; episteme is seen as a form of elite knowledge that is evident in the education of kindergarten pedagogues (often at the degree level), while techne (skills) is evident in the vocational 
training of those working in childcare. Andrew's distinction acknowledges a split model of care and education services (Bennett, 2003), which, while evident in many European countries (European Commission, 2014), is a model no longer favoured by the European Commission. Writing in the Australian context, Andrew acknowledges that the forging together of episteme and techne will be challenging, but wider debates on professionalism identify the need for both knowledge and skills-know-that and know-how (Winch, 2014; Young \& Muller, 2014). The combination of know-that and know-how demonstrates how ECEC professional knowledge is multiple and varied. The combination of knowledges (in different forms) begins the process of recognizing the different knowledge structures that exist (Bernstein, 1999) within a professional knowledge base, but still leaves a need to consider the knowledges that remain unrecognized and undervalued in ECEC.

The historical favouring of episteme and techne is evident in discussions of the knowledge base for ECEC. As discussed, child development theories have been prominent because they represent knowledge that has value and significance (Hordern, 2016), but they require know-how (Young \& Muller, 2014) to meet the demands of professional practice. Kalliope Vrinioti (2013) writes of ECEC professionalism:

No matter what definition of profession and professionalism one chooses from whatever ideological or epistemological starting point (Urban 2008), it seems that all agree that the main feature of professionalism is the implementation of scientific knowledge towards solving today's problems by using reflective ability. (p. 158)

However, the predominance of "scientific knowledge" as underpinning ECEC professionalism has sat uneasily with professionals, with concerns as to what is lost, particularly that which relates to a more ethical construct (Dahlberg \& Moss, 2005). An ethics of care considers the conditions of ECEC critically, conceptualizing knowledge as plural (knowledges), thus opening up the possibility of ways of knowing beyond those set out in modernist models. The plurality is not a rejection of one form of knowledge for another, but a recognition of knowledge as contestable and plural. The plurality of knowledge means that ethics are not universal principles that can guide people in a rational way; instead, multiple ways of knowing will be shaped by many factors, including individual experiences and cultural context. The emphasis on ethics is not to the exclusion of theory in professionalism (Young \& Muller, 2014), but is an appreciation of multiple forms of knowledge for working in ECEC.

The knowledges evident in ECEC illustrate the different forms of knowledge present in Bernstein's framework. Mathias Urban and colleagues (2011) identified a range of forms of knowledge in the ECEC competence profiles for individuals in different European countries, such as knowledge of holistic child development, learning strategies, communication with children, working with parents and communities, working collaboratively, and health, safety and child protection requirements. Mary Moloney (2010) refers to the complexities of both understanding and applying child development knowledge to facilitate professionals in providing appropriate resources, while simultaneously thinking about the learning environment and differentiating the needs of the children within it. Linda Miller (2008) considers how the ECEC knowledge base extends beyond child development to include knowledge of the setting, children, and families, while also including leadership, management, and organizational skills. The varying knowledges reflect the coming together of know-that and know-how, whereby vertical and horizontal knowledge combine to inform professional practice. However, more than just episteme and techne are embedded in the knowledges identified.

Urban and colleagues (2011) also refer to values in their analysis of competence profiles, while Miller (2008) considers dispositions as important for professionalism. Variable terms, including sensitivity, empathy, awareness, respect for others, commitment to the early years field, and confidence (Miller, 2008), as well as love, reflection, wanting to make a difference, passion, warmth, being emotionally accessible, and emotional intelligence (Georgeson 
et al., 2014), have all been identified in the context of ECEC professionalism in England. The list of terms does not assume universality, but provides evidence of something beyond episteme (pure knowledge) and techne (skills) as part of ECEC professionalism-phronesis.

Phronesis (practical wisdom) is not concerned with a particular end goal, but guides one in how to do things in pursuit of a good life (Russell, 2014). Phronesis relates to both the individual and the universal, taking the context as well as the interpersonal relationship between the professional and the child into account to provide "a family of skills that all aim in an intelligent, perceptive way at finding what it would be beneficial to do within the here and now" (Russell, 2014, p. 206). Phronesis is not a question of responding to a child, but of how to respond to a child, in relation to both the individual and universal child, such as with empathy, sensitivity, and warmth. Phronesis is acquired through experience and is deliberative, but a lack of articulation of its deliberations does not mean it is absent (Finnigan, 2015).

\section{Learning and displaying phronesis}

Despite my emphasis on phronesis as deliberative (learned, intentional, and purposeful), it is often presented as an innate, gendered ideal. However, identifying phronesis as learned is important for later considering its discourse and structure in relation to Bernstein's theory. Research evidence demonstrates that those undertaking vocational ECEC training consider caring to require innate, embodied characteristics. Theoretical knowledge is downplayed and practical experience is valorized (Skeggs, 1997; Vincent \& Braun, 2011). Caring is regarded as a natural ability aligned with femininity, whereby personal dispositions characterize and are inseparable from a construction of a good care worker (Skeggs, 1997). Feminist arguments identify the long history of classifying the moral actions of women, whereby women are given constant messages about right and wrong behaviours that are closely aligned to cultural discourses on femininity and motherhood. The gendered ability to care has also been associated with social class, with a shift from wealthy philanthropists providing services for children deemed in need to workingclass women providing ECEC services for middle-class women who are employed. The perspectives on social class illustrate an interest in the professionalism of the ECEC workforce from beyond the sector (Skeggs, 1997). While this interest remains, it is no longer always characterized by social class; instead policy initiatives increasingly characterize external influences on ECEC professionalism.

Helen Colley (2006) discusses how training reinforces a constructed ideal of those who work in ECEC via a hidden curriculum that ratifies correct behaviours. A vocational habitus encapsulates the combination of idealized and realized dispositions to which students orientate themselves in order to become the "right person for the job." Far from being innate, the moral behaviours for ECEC are socially constructed, embedded in understanding the other (both the individual and universal), and learned through interactions with those also undertaking their training, with experiences of being in the workplace, and with broader (gendered) messages of right and wrong behaviours. The vocational habitus may vary among the levels of qualifications that exist for those training to work in ECEC and/or among the different professional roles, but it demonstrates the learning, experiential, and deliberative excellence of phronesis, which challenges the innate, gendered ideal.

Illustrating that the ideal is learned is significant, both for recognizing the demands of coming to know-how to work in ECEC and also for challenging assumptions of who is an ECEC professional. Many countries report that nearly all staff working in direct contact with children are women, (European Commission, 2014), and as Vandenbroeck and Peeters (2008) explore, modelling the profession on a mother-like ideal is likely to reinforce gender segregation. Both Vandenbroeck and Peeters (2008) and Vincent and Braun (2011) argue that within ECEC training there are implicit assumptions, particularly among students, about the right person for the job 
that are highly gendered. Research with male students draws attention to men being branded as the "wrong" kind of person, with concerns that they will be labelled as either homosexual or a pedophile for working with young children (Vincent \& Braun, 2011). Despite these concerns, Charlotte Jones (2015), in her survey of men working in ECEC, finds that her participants were motivated by "a love of children" (p. 12), suggesting that the ideal is not gender exclusive. However, the vocational habitus, in which individuals become the right person for the job, illustrates that the ideal is learned. Colley (2006) writes:

Even the most "suitable" girls have to adapt their dispositions further as they encounter the emotional challenges of the workplace. The pragmatic detachment required to cope with "puke", "pee," and punches is mitigated by the idealised image of the perfectly sensitive and gentle nursery nurse, and by the deeply caring culture created by college tutors. (pp. 24-25)

Presenting ECEC as requiring innate abilities masks the challenges identified by Colley of coming to know-how to work in ECEC.

While Colley (2006) draws attention to the role of the workplace and training institutions in contributing to how professionals learn the ideal, parents and the cultural context also interplay. Increasingly, ECEC research emphasizes the emotional challenges of working with children, much of which centres on learning appropriate emotional responses (Elfer, 2015). Jools Page (2011), while emphasizing the importance of the relationship between professionals and the child, has indicated that there is less certainty as to whether parents expect the relationship to include love. Page argues for "professional love," but given the debates on professionalism, what it means, and whether it is a constraining construct, it might be that professional is not the right term for understanding the emotional complexities of working in ECEC. There is a risk that professional love becomes technocratic in its approach (as with other debates on professionalism) or is separated from wider discussions and definitions of a professional knowledge base.

I accept that there are cultural norms to learning appropriate behaviours, particularly when it comes to interacting with children, but I do not position phronesis as an anti-intellectual process of fitting in to the norms. The process of fitting in is a careful and considered act, focused on an ethics of care that incorporates multiple forms of knowledge. In work previously undertaken with colleagues (Campbell-Barr, Georgeson, \& Nagy Varga, 2015), we highlighted the question faced by students undertaking training in England as to whether a hug is an appropriate emotional response to a child falling over. Conversely, in Hungary, physical signs of affection are accepted within their ECEC traditions (Campbell-Barr et al., 2015). Our conclusions emphasized the consequences of the cultural context, culturally appropriate terminology, historical events that shape concepts of childhood (such as highprofile child protection cases), and policy developments for informing understandings of professional emotional responses. While neither Page (2011), Colley (2006), nor Campbell-Barr et al. (2015) refer to phronesis, they indicate the need to recognize something beyond episteme and techne for working in ECEC, much of which relates to appropriate emotional responses in the relationship with the child. The learning of correct responses in a context demonstrates phronesis as deliberative intelligence, whereby it is considered, intentional, and purposeful. Moreover, phronesis as know-that is not sufficient. Professionals also need experiential know-how in developing their professional knowledges.

\section{Emotion as a commodity}

Learning the correct responses and becoming the right person for the job are also evident in perspectives that have identified emotional responses as a commodity. Perspectives on emotions as a commodity have positioned emotions as either something that is exploited by an employer or something of value to the employee. For example, 
Arlie Russell Hochschild's (2003) “feeling rules" emphasized learning and displaying emotional responses as being a "cost" to the employee. An employee learns to regulate their emotions in a way that is of economic gain for the employer, but not the employee. Conversely, recognizing the rewards of emotional labour and being consciously aware of emotions and the day-to-day decisions that are made regarding them enables individuals to make use of emotions as emotional capital (Andrew, 2015). Andrew explores emotional capital in relation to phronesis to account for how the response to one child may not be the same as the response to another child in the same situation. Instead, emotional responses are considered actions, developed through self-reflection. Prior emotional interactions provide insights for how to respond in subsequent emotional interactions. Therefore, emotional responses are not innate, but are skills to be practised within the social context. For Andrew (2015), learning about and understanding emotional responses prevents exploitation. However, to understand phronesis as capital, the interpersonal and relational aspects of ECEC must be seen as commodities that are traded, potentially positioning emotional interactions within an economic perspective that challenges the moral construct of phronesis, given that economics is aligned to the technocratic, rational professionalism of modernism (Osgood, 2004). Rather than phronesis being aligned to technocratic professionalism, I would suggest that perspectives on emotion as a commodity illustrate the interplay between know-that and know-how. The know-that of phronesis will not meet the demands of professional practice. Instead, experiences in the field of practice will refine professional knowhow, illustrating the complexities of professional knowledges for ECEC.

\section{The language of knowledge}

Andrew (2015) acknowledges how his discussion of emotional capital is bound by the language available. I also believe language limits the elaboration of phronesis. Christopher Winch (2014) discusses the fact that within professional roles there will be personal characteristics that go beyond the identification of skills, but often we just do not have words for them. Inevitably there is a cultural turn to the terminology used, and even the use of the English language in writing a paper on knowledges impacts the concepts it is possible to discuss. Take for example the use of love. In Greek four words are available to express love: agápe, éros, philía, and storgē. While the cultural context is important for understanding the application of these four forms of love, as an English writer I have one word. Cultural should not be confused with national. There will be local cultures that those working in ECEC will be negotiating in forming an understanding of their role, such as seeking to understand the families in their community. Those working in ECEC therefore find themselves negotiating the cultural context, learning about phronesis through the experience of emotional interactions developed through self-reflection. However, language presently limits both an articulation and an analysis of experiences relating to phronesis. For example, someone can produce an emotional response befitting the context (such as to a child falling over), but this does not mean it can be described. In modernist terms, the tacit nature of the knowledge means that it cannot be measured and assessed, and it is therefore marginalized in understandings of professionalism.

There is a danger that the exploration of phronesis could get caught up in semantics, but the variable (and potentially insufficient) terminology used to describe a body of knowledge that extends beyond episteme and techne is one difficulty with recognizing this form of knowledge. Without an agreed-upon (or common) language to discuss this knowledge, it is intangible. Further, the innate construct limits explicit evidencing of the presence of phronesis either in relation to what it is or how it is acquired. The knowledge base risks becoming a folk pedagogy, an everyday construction of the knowledge required for ECEC, representing a set of assumptions that those working in ECEC bring with them regarding children and teaching and learning (Bruner, 1996). Finding a language for phronesis is not about enabling researchers to identify and classify it, but about enabling a full appreciation of the complexities of working in ECEC and the knowledges required for this role. 


\section{Bernstein and knowledges}

The discussion of phronesis demonstrates that there are knowledges that ECEC professionals develop that extend beyond episteme and techne. Techne and episteme reflect the multidisciplinarity of ECEC (Rhedding-Jones, 2005) and the requirement for knowledge to be applied within professional contexts. There is a temptation to position phronesis in the horizontal discourse in recognition of its practicality, everyday derivation, and taken-forgrantedness. However, the deliberations, judgments, and action that relate to phronesis (Breier \& Ralphs, 2009) are an example of Bernstein's vertical knowledge.

Phronesis represents vertical knowledge with a segmented structure and weak grammar, represented by the challenges of articulating and interrogating it. While the use of attitudes, dispositions, values, and an ethic of care are illustrative of the weak articulation of the know-that of phronesis, they provide a set of propositions as to what should be included in ECEC professionalism. However, knowledge alone is not enough in a professional context, so phronesis requires practical action whereby a phronetic approach forms a link between reason and emotions. Bernstein never explicitly mentions phronesis, but I believe it is a key component in the recontextualization and application of knowledges, whereby professionals draw on a range of knowledges to meet the needs of practice.

Know-how therefore includes the application of phronesis, illustrated by the references to being caring, loving, empathetic, etc., discussed earlier. As illustrated, the emotional characteristics of phronesis may make them hard to articulate, but they remain central to the ECEC knowledge base. There is a need to elaborate both the knowthat and know-how of the ECEC knowledge base to develop a more elegant articulation of the knowledges for working in ECEC (Winch, 2014). I recognize that my assessment of the knowledges for ECEC is bound by the social processes of legitimizing knowledge, but just because something cannot be scientifically proven is not to say it is not there (Young \& Muller, 2007).

Understanding ECEC as a region enables professionals to draw upon a long history of theoretical knowledge from various disciplines while also recognizing phronesis in meeting the demands of professional practice. Phronesis and "pure knowledge" are integrated, whereby the former is needed to make sense of the latter (Winch, 2014). However, because of the array of languages as a result of vertical discourse, segmentally organized and with differing grammars, the recontextualization involves a process of selection (Bernstein, 2000). The selection process can be shaped by external factors, such as market forces or policy requirements, but the choice of an individual can also shape the knowledge combinations and their recontextualization. There is a danger of rogue theories, whereby particular ideals are upheld, but without scrutiny or evaluation. For example, the innate, gendered ideal is a rogue theory that masks the learned nature of phronesis while potentially excluding men from ECEC. Therefore, identifying the presence of phronesis for ECEC professionals is not sufficient. It requires articulation, both in regards to what it is and to how it is applied and evaluated to develop legitimacy and avoid rogue theorizing.

\section{Conclusion}

Bernstein's contribution to understanding the knowledge of professionalism offers the potential to recognize the importance of phronesis in ECEC. However, the language of phronesis is problematic for discussing what this form of knowledge is and how it is acquired and applied. Knowing is clearly more than having theory. It will depend on personal characteristics (Winch, 2014) and be drawn from experiences, both in the wider society and from the daily experiences of working with children (Colley, 2006; Skeggs, 1997). Phronesis is therefore not innate. Instead, the ECEC professional is shaped by the cultural context in determining appropriate emotional responses. The emphasis on knowledges and the importance of knowledge combinations illustrates that there are not singular right and wrong emotional responses for working in ECEC. Considering ECEC professional knowledge in the 
plural broadens perspectives on the ECEC knowledge base and opens up discussions about how different forms of knowledge are acquired and combined.

Recognizing ECEC professionalism as requiring knowledges (episteme, techne, and phronesis) has consequences for how professional learning is conceptualized. Importantly, the incorporation of phronesis acknowledges the emotional challenges of learning to work with young children and that becoming the "right" ECEC professional is a careful and deliberative process. ECEC training programs should consider the place of phronesis within ECEC professional knowledges, exploring the complexities of coming to know-how to work with young children, while beginning a process of professionals articulating and scrutinizing all aspects of the ECEC knowledge base. 


\section{References}

Andrew, Y. (2015). What we feel and what we do: Emotional capital in early childhood work. Early Years, 35(4), 351-365. doi:10.1080/0 9575146.2015 .1077206

Bennett, J. (2003). Starting strong. Journal of Early Childhood Research, 1(1), 21-48. doi:10.1177/1476718x030011006

Bernstein, B. (1999). Vertical and horizontal discourse: An essay. British Journal of Sociology of Education, 20(2), 157-173.

Bernstein, B. (2000). Pedagogy, symbolic control, and identity: Theory, research, critique (rev. ed.). Lanham, MD: Rowman \& Littlefield.

Breier, M., \& Ralphs, A. (2009). In search of "phronesis": Recognizing practical wisdom in the recognition (assessment) of prior learning. British Journal of Sociology of Education, 30(4), 479-493. doi:10.1080/01425690902954646

Brock, A. (2006). Dimensions of early years professionalism: Attitudes versus competences? Retrieved from https://tactyc.org.uk/pdfs/ Reflection-brock.pdf

Bruner, J. S. (1996). The culture of education. Cambridge, MA: Harvard University Press.

Cameron, C., \& Moss, P. (2007). Care work in Europe: Current understandings and future directions. London, UK: Routledge.

Campbell-Barr, V. (2012). Early years education and the value for money folklore. European Early Childhood Education Research Journal, 20(3), 423-437. doi:10.1080/1350293x.2012.704764

Campbell-Barr, V., Georgeson, J., \& Nagy Varga, A. (2015). Developing professional early childhood educators in England and Hungary: Where has all the love gone? European Education, 47(4), 311-330. https://doi.org/10.1080/10564934.2015.1100451

Colley, H. (2006). Learning to labour with feeling: Class, gender, and emotion in childcare education and training. Contemporary Issues in Early Childhood, 7(1), 15-29. doi:10.2304/ciec.2006.7.1.15

Cottle, M., \& Alexander, E. (2012) Quality in early years settings: Government, research, and practitioners' perspectives. British Educational Research Journal, 38(4), 635-654.

Council of the European Commission. (2011). Council conclusions on early childhood education and care: Providing all our children with the best start for the world of tomorrow. Retrieved from https://publications.europa.eu/en/publication-detail/-/publication/ f9674565-5714-4453-8dd1-72126e63b423/language-en

Dahlberg, G., \& Moss, P. (2005). Ethics and politics in early childhood education: London, UK: RoutledgeFalmer.

Dahlberg, G., Moss, P., \& Pence, A. (2013). Beyond quality in early childhood education and care: Languages of evaluation ( ${ }^{\text {rd }}$ ed.). London, UK: Routledge.

Dalli, C. (2014). Quality for babies and toddlers in early years settings. TACTYC Occasional Paper 4. Retrieved from http://tactyc.org.uk/ wp-content/uploads/2014/04/Occ-Paper-4-Prof-Carmen-Dalli.pdf

Elfer, P. (2015). Emotional aspects of nursery policy and practice: Progress and prospect. European Early Childhood Education Research Journal, 23(4), 497-511. doi:10.1080/1350293X.2013.798464

European Commission. (2014, June). Key data on early childhood education and care in Europe 2014 Edition. Eurydice and Eurostat Report. Retrieved from https://ec.europa.eu/eurostat/documents/3217494/5785249/EC-01-14-484-EN.PDF/cbdf1804-a13943a9-b8f1-ca5223eea2a1

Finnigan, B. (2015). Phronēsis in Aristotle: Reconciling deliberation with spontaneity. Philosophy and Phenomenological Research, 91(3), 674-697. doi:10.1111/phpr.12126

Florian, L., \& Graham, A. (2014). Can an expanded interpretation of phronesis support teacher professional development for inclusion? Cambridge Journal of Education, 44(4), 465-478. doi:10.1080/0305764X.2014.960910

Gade, S. (2014). Praxis and phronesis as units of analysis: Realising a social science that matters in practitioner inquiry. Reflective Practice, 
15(6), 718-728. doi:10.1080/14623943.2014.944129

Georgeson, J., Campbell-Barr, V., \& Mathers, S. with Boag-Munroe, G., Parker-Rees, R., \& Caruso, F. (2014, November). Two-year-olds in England: An exploratory study. Retrieved from http://tactyc.org.uk/wp-content/uploads/2014/11/TACTYC_2_year_olds_ Report_2014.pdf

Hochschild, A. R. (2003). The managed heart: Commercialization of human feeling. Berkeley and Los Angeles: University of California Press.

Hordern, J. (2016). Knowledge, practice, and the shaping of early childhood professionalism. European Early Childhood Education Research Journal, 24(4), 508-520. doi:10.1080/1350293X.2014.975939

Hordern, J. (2017). Bernstein's sociology of knowledge and education(al) studies. In J. Furlong \& G. Whitty (Eds.), Knowledge and the study of education: An international exploration. Oxford, UK: Symposium Books.

Jones, C. E. (2015). “...For the love of children and the joy of childhood”: The reported values, beliefs, and practices of male practitioners within early childhood education and care in England. Journal of Early Childhood Research, 14(4). doi:10.1177/1476718x15577005.

Miller, L. (2008). Developing professionalism within a regulatory framework in England: Challenges and possibilities. European Early Childhood Education Research Journal, 16(2), 255-268. doi:10.1080/13502930802141667

Moloney, M. (2010). Unreasonable expectations: The dilemma for pedagogues in delivering policy objectives. European Early Childhood Education Research Journal, 18(2), 181-198. doi:10.1080/13502931003784362

Moyles, J. (2001). Passion, paradox and professionalism in early years education. Early Years, 21(2), 81-95. doi:10.1080/09575140124792

Oberhuemer, P., Schreyer, I., \& Neuman, M. (2010) Professionals in early childhood education and care systems: European profiles and perspectives. Leverkusen Opladen, Germany: Barbra Budich.

Osgood, J. (2004). Time to get down to business? The responses of early years practitioners to entrepreneurial approaches to professionalism. Journal of Early Childhood Research, 2(1), 5-24. https://doi.org/10.1177/1476718X0421001

Osgood, J. (2006). Professionalism and performativity: The feminist challenge facing early years practitioners. Early Years, 26(2), 187-199.

Osgood, J. (2014). Playing with gender: Making space for post-human childhood(s). In J. Moyles, J. Payler, \& J. Georgeson (Eds.), Early years foundations: Critical issues (pp. 191-202). Berkshire, UK: McGraw Hill Education.

Page, J. (2011). Do mothers want professional carers to love their babies? Journal of Early Childhood Research, 9(3), 310-323. doi:10.1177/1476718x11407980

Rhedding-Jones, J. (2005). Decentering Anglo-American curricular power in early childhood education: Learning, culture, and "child development" in higher education coursework. Journal of Curriculum Theorizing, 21(3), 133-133.

Russell, D. (2014). Phronesis and the virtues (NE vi 12-13). In R. M. Polansky (Ed.), The Cambridge companion to Aristotle's Nicomachean ethics. Cambridge, UK: Cambridge University Press.

Skeggs, B. (1997). Formations of class and gender: Becoming respectable. London, UK: SAGE.

Urban, M. (2008). Dealing with uncertainty: Challenges and possibilities for the early childhood profession. European Early Childhood Education Research Journal, 16(2), 135-152. doi:10.1080/13502930802141584

Urban, M., Vandenbroeck, M., Lazzari, A., Peeters, J., \& van Laere, K. (2011). Competence requirements in early childhood education and care (CoRe). European Commission Directorate-General for Education and Culture. Retrieved from https://download.ei-ie.org/ Docs/WebDepot/CoReResearchDocuments2011.pdf

Vandenbroeck, M., \& Peeters, J. (2008) Gender and professionalism: a critical analysis of overt and covert curricula. Early Child Development and Care, 178(7-8), 703-715.

Vandenbroeck, M., Peeters, J., \& Bouverne-De Bie, M. (2013). Lifelong learning and the counter/professionalisation of childcare: A 
case study of local hybridizations of global European discourses. European Early Childhood Education Research Journal, 21(1), 109-124. doi:10.1080/1350293X.2012.760339

Vincent, C., \& Braun, A. (2011). "I think a lot of it is common sense...": Early years students, professionalism, and the development of a "vocational habitus." Journal of Education Policy, 26(6), 771-785. doi:10.1080/02680939.2010.551143

Vrinioti, K. (2013). Professionalisation in early childhood education: A comparative view of emerging professional profiles in Germany (Bremen) and Greece. European Early Childhood Education Research Journal, 21(1):150-163. doi:10.1080/1350293X.2012.760343.

Winch, C. (2010). Dimensions of expertise: A conceptual exploration of vocational knowledge. London, UK: Bloomsbury.

Winch, C. (2014). Know-how and knowledge in the professional curriculum. In M. Young \& J. Muller (Eds.), Knowledge, expertise and the professions (pp. 47-60). London, UK: Routledge.

Young, M., \& Muller, J. (2007). Truth and truthfulness in the sociology of educational knowledge. Theory and Research in Education, 5(2), 173-201. doi:10.1177/1477878507077732

Young, M., \& Muller, J. (2014). From the sociology of professions to the sociology of professional knowledge. In M. Young \& J. Muller (Eds.), Knowledge, expertise and the professions (pp. 3-17). London, UK: Routledge. 